DOI: $10.1515 /$ rpp-2016-0045

PhD in Humanities, Senior Instructor, DOROTA JANKOWSKA The Maria Grzegorzewska University in Warsaw, Poland Address: 40 Szczesliwicka St., Warsaw, 02-353, Poland, E-mail: djankowska@aps.edu.pl

Dr hab. Prof. APS, MACIEJ TANAŚ

The Maria Grzegorzewska University in Warsaw, Poland Address: 40 Szczesliwicka St., Warsaw, 02-353, Poland, E-mail:mctanas@gmail.com

\title{
NEW TECHNOLOGIES AS A TOOL FOR CHANGING ACADEMIC COMMUNITIES IN THE GLOBAL CONTEXT
}

\begin{abstract}
It has been defined that knowledge society emerges at the end of the twentieth century as the socio-economic structure characteristic for developed societies in which unlike in industrial societies, the dominant sector of economy is services and the largest social group is the "men of knowledge". It has been indicated that the development of the knowledge society is considered in connection with scientific and technological development and the expansion of new technologies as they determined is that we live in a globalized world, connected by a dense network of connections and intensive contacts both between the individuals and the authorities at local, regional, national and transnational or institutions level or between the institutions of various types, among which, of course, there are also educational institutions, including universities. It has been concluded that the accentuated thought should be read as a contemporary call for the implementation of the classic academic ideas in the conditions of the use of new technologies. Paraphrasing a metaphor of J. Morbitzer, modern university institutions should become intellectual arcs that will save humanity from the information deluge, the flood of endless, murky waves to safely bring it to the port of the society in which knowledge will be a resource for creative and innovative activities. A very important task is in the situation of current unprecedented acceleration of technical and technological progress not to lose the deep humanistic character of the educational process in which the modern technology should well serve a man and not contribute to its enslavement.

Key words: knowledge society, academic community, technology, education, academic education.

\section{INTRODUCTION}

A common term used to describe contemporary reality is an ascertainment that it is in the process of becoming a knowledge society. P. F. Drucker (1969) defines the knowledge society that emerges at the end of the twentieth century as the socio-economic structure characteristic for developed societies in which unlike in industrial societies, the dominant sector of economy is services and the largest social group is the "men of knowledge". He calls them the technicians because they have the expertise which they are able to use to solve current problems and which they are continually expanding. The characteristics of the knowledge society in addition to these above mentioned features,
\end{abstract}


embrace the particular importance of knowledge (Machlup, 1980) and its potential in making innovation as well as an increasing role of educational institutions (Morbitzer, 2009). Treating knowledge as the main resource, capable of intensifying economic development by far more than labour, capital and raw materials - in the centre of attention are the institutions established in order to generate, develop, accumulate and transfer knowledge in the same time educating both in terms of its effective use. These institutions are primarily universities and other academic institutions, after all, for centuries considered as "the centres of knowledge", responsible for its creation, development and today also for its popularization, commercialization and transfer to a wide public circulation. Hence, it is the age of the twenty-first century, which is sometimes referred to as the century of universities. In the same century for the first time in the history, the academic education has become open (and recommended) for all, acquiring the nature of mass education.

\section{THE AIM OF THE STUDY}

The aim of the study consists in revealing the role of new technologies as a tool for changing academic communities in the global context.

\section{THEORETICAL FRAMEWORK AND RESEARCH METHODS}

It should be noted that many theoreticians and social researchers also in Poland present a distanced stance on the feasibility of the implementation of the idea of the knowledge society and see in uncritical and often manipulative referring to no serious threats, a danger for spiritual values and academic culture at universities. A. Lipski suggests that treating knowledge as a resource, subjected to rational management procedures, leads to its reification, utilitarianism and commodification (Lipski, 2014). The process of creating knowledge begins to be perceived as a scientific production, the quality of which is estimated by technocratic manners, taking into account what is actually important for the creators of measurement, not necessarily - for the good of the science development revealing in the long term. The academic education itself according to its etymology being a process of achieving knowledge and personality development of students through their participation in the pursuit of knowledge (studiosus [Lat.] - zealous, eager for knowledge) and experience of coexistence and cooperation in the scientific community, is subordinated to the external processes of the management, which is in fact, an expression of power and hegemony of the economy. This results in the perception of the academic education "as an investment into future, perception of the diploma as a market commodity and the sector of higher education investments as a discipline of industry and the market economy" (Misztal, 2000).

Our study has been performed with the use of such methods as analysis and synthesis, induction and deduction, systematization and generalization.

\section{RESULTS}

The development of the knowledge society is considered in connection with scientific and technological development and the expansion of new technologies. They determined this that we live in a globalized world, connected by a dense network of connections and intensive contacts both between the individuals and the authorities at local, regional, national and transnational or institutions level or between the institutions of various types, among which, of course, there are also educational institutions, including universities. As a result of the growing network of links, information flow comes into being and specific, but nevertheless real and dynamic forms of exchange and cooperation and coacting. Thinking about the network as the reaping of information points to its educational potential also raises questions about the relationships that exist between the specificity of the user seeking information in the network and studiosus seeking for wisdom between the cultural meaning of the existence of open information network and academic communities, 
created for "advancing knowledge forward". In the context of reflection on the state of academic education in the age of digitization, the commonly asked questions are whether the new technologies and digital networks are a factor contributing to the quality of education or they rather carry risks. Is it a tool in the hands of the ideology of building a knowledge society (rather society whose economy is based on knowledge) or can it be used to enhance the strength of academic communities, trying to make the world more understandable, in line with the idea of universitas [Lat.] - combined reality; universe, accumulated commonality about the world of knowledge.

The academic life traditionally developing within the higher education schools, guided the entire academic community in the area of the world of spiritual values, exceeding the realm of self-interest. For centuries, the academic graduates had to be in first place wise and ethical persons and these qualities are shaped by the academic experience gained through encounters with the knowledge. It is an experience of different quality than the contact with information, even if it is impressive in terms of quantity and the degree of detail or attractiveness of technical transmission.

The developers of the ideology of building a knowledge society point to the special role of universities, but often they limit this role to vocational training - training technicians, experts (Rifkin, 2001). The trend observed in Poland: the end towards professionalization of higher education is combined with treating academic education in terms of educational investment - achieving competitiveness on the labour market. The task of vocational training, however, was not in the tradition of university education as primary goal as it seems to be today. University studies were primarily to educate the elite of the society, and thus referring to the definition of elites ( $D^{\prime}$ elite [Fr.] - the subject of the highest grade and of the best choice) - groups of people who are able to excel above short-term benefits, thinking critically and creatively, who initiate action adequate for the roles performed in the variable and risky social reality (Giddens, 2001). With the new conditions, more complicated by mass character of education, will they do? Can the presence of new technologies influencing both the way of learning and dissemination of its results and the very process of learning itself be a factor supporting the training of new elites?

Although digitization in itself is an expression of scientific and technical progress in the eyes of critics, it appears to be a work created by man, which turns against humanity, destroying the humanistic spirit of human reflection and sensitivity. Numerous studies have shown that young users of new technologies, described by M. Prensky as "digital natives", in their mass they remains incapable of deep reflection, of generalization as well as generalization about conclusions. They have narrow cognitive horizons - cannot accept a broader point of view, and their attention is short and dispersed (Carr, 2013). Due to the overload of ubiquitous information "the brains of digital natives work in the so-called emergency mode, in which there occurs a disconnection of the prefrontal cortex, i.e. part responsible for empathy, altruism and tolerance. As a result of this process there occurs in these people: the difficulty in communicating feelings, difficulty in understanding someone else's different point of view, difficulty in maintaining social relationships and thus they are more and more like autistic persons. It is also mentioned that it the most narcissistic generation in history, inward-looking, convinced of their uniqueness, expecting admiration from their community and in consequence treating others with admiration" (Carr, 2013; Musial, 2013).

The optimists suggest that the number of people rationally enjoying the benefits of communication network, involved in the processing and transmission of information is increasing (Lesniewski, 2013). These "super-connected" with optimism and will to take action look into the future. They believe in the power of democracy and grass-roots 
initiatives, expressing readiness for cooperation and joint action, primarily these that combine the knowledge sharing. They seek knowledge for themselves, which is of interest to them, corresponding to their personal needs. They seem to be studiosus community, which poses higher and higher requirements and seeks wisdom. In that quest they search for contacts and establish them in the virtual network, which, after all, they can also expand by direct contacts, relationships initiated in the network tend to be developed in real space and vice versa. The network users who are studiosus represent a new approach to cooperation and knowledge sharing. They love to personalize and customize the inflow of information to their needs, hence but also they want entertainment and fun (Hausman, 1999; Cudowska, 2011; Tapscott, 2010).

So, do the new technologies impair cognitive processes and weaken interpersonal relationships or develop skills to learn in open space together with others?

It is clear that these concerns cannot be resolved unequivocally. No doubt those new technologies are extremely important in the process of social change, development of science and academic education, however it is not reasonable to perceive them as direct causes of changes. They pose a necessary condition for changes, after all, not sufficient for their occurrence (Morbitzer, 2014). Paul Levinson (1999), a supporter of the so-called, soft media determinism proves that media and new technologies enable and stimulate the occurrence of major social events (also educational), however, their form and the consequences resulting from them are not simple consequences of applied technology; in other words - the new social states are consequences of other factors than just technology. There is no automatism between the use of new technologies and becoming a cognitive cripple, as there is no direct link between the drawing on the abundant information resources and the attainment of wisdom.

What can the new technologies enhance in educational process developed in the universities? What is the basis of their strength? Is it the fact of making the inexhaustible resource of information, seductive by its appeal in the form of its presentation, positive attitude and willingness of young people to participate in it? In the belief presented here, the main potential is building the opportunities and strengthening the ties and rebuilding of the community cooperation - often in spite of subcutaneously implanted (hidden under the banner of the need for knowledge management) tendencies of its commodification and instrumentalization, fuelling the atmosphere of competition and competitiveness. The network helps building the community by improving the old and delivery of new communication tools, by creative activity of its participants and sharing its effects, in words, by sharing polisensoric information and knowledge beyond geographical, political or economic boundaries. It creates a unique opportunity of author's expression by expressing own experiences, thoughts and assessments in the network community. It is obvious that new technologies can also be used for propaganda and manipulation, or (what is often forgotten) for supervision or control. It is not an argument that the anonymity of network (apparent anyway) triggers behaviour characterized by hostility, will of destruction and the digitalization of contact causes technicality and objectivising the attitude towards people. If such behaviour and attitudes are evoked and the network is used against man, than - in reference to the quoted Lewison - the sources of such practices should be looked for deeper, beyond the properties of the network.

Hence, expressing dissatisfaction with the changes which we observe in the area of academic culture, they should not be seen only in the context of the progressive digitization, development and ubiquity of networks and giving media power to educational processes. Perhaps, it is worth screening more critically the circumstances of expansion of 
the ideology of building a knowledge-based society (or rather: the society of the knowledge economy) and processes of progressive commodification of science and its commercialization? Maybe, the mechanisms that cause disturbance of traditional values and the weakening of ties, endangering the academic communities are embedded in them? The new technologies are (after all, only) unique tools, for the use of which one shall be particularly carefully prepared so that they remain at the disposal of human wisdom.

One can specify many spectacular examples testifying the fact that new technologies are present in academic reality.

Most often, their role is indicated in the creation of commonly accessible human space of knowledge and culture and improving the possibility of using e-resources. For many of them, thanks to the acquisition of their free licenses or transfer to the public domain and making available by any ICT technologies - there is a fully open access. They form the OER (Open Educational Resources), created in response to the demands of the creation of shared universal educational resources available for the whole humanity and the hope that this open source in future will mobilize the whole of the world community of teachers (UNESCO, 2002). The Organisation for Economic Cooperation and Development (OECD) defines OER as "free and open access to digital materials for teachers, students and self-study as well as their use for teaching, self-learning and research. OER includes the learning content, tools for development, use and dissemination of content and such resources as open licenses".

Increasingly, we find examples of the creation of professionally produced interactive platforms for university courses. Massachusetts Institute of Technology announced the launch of MITx (Massachusetts Innovation \& Technology Exchange), of which the users can remotely access the materials and courses taught at this university, use virtual laboratories and contact with their colleagues (Błoński). The students are assessed and those who meet the requirements of the university receive a certificate of its completion. The software is available free of charge. The MIT initiative complies with the idea of MOOC (Massive Open Online Course) - mass, public courses on the Internet. The modern tools of ICT technologies provide not only interactivity of these courses, but also through programs of communication and social networking allow the building of academic community of students and professors. It is worth noting that from May 2012 the above mentioned university in conjunction with Harvard University launched a joint project called EDX. The objective was the implementation of online free university courses within the range of many disciplines for students from around the world and conducting research in the learning process. The universities and colleges, which make up the consortium, are among the most prestigious in the world, and the projects inspired by them - like Khan Academy - have very high educational value.

Recently, we have observed the development of OER and the initiatives undertaken by the world's major centres of research, such as: EDX, COURSERA or UDACITY, make the issue of public, interactive and polysensoric, distance learning, parallel education and self-education become one of the most important educational challenges of our time faced by academia. The use in relation to the Universities of the term "University 2.0" to follow the pattern of the term of WEB 2.0" describes it eloquently. It may be recalled that the concept of Web 2.0 describes these websites that use new technologies that allow for interaction and cooperation in social dialogue of the network users, unlike traditional websites, allowing only a passive reception of posted content. Tomasz Goban-Klas, seeing a limitation in marketing referring to strict programming nomenclature, proposes a new model of university called "University NeXT". The addition of the letters NeXT - has symbolic meaning: NT-means new technologies, ext-derived from extended, net-network and next (Goban-Klas, 2013). This new generation of 
university recognizes the value of tradition of unity between the teaching and learning. It stems from belief in natural desire to get to know professors and students. "It combines the study offline, traditional and direct from online study, but solid and creative. It is a veritable university transmitting not only knowledge, but also the values of knowledge, including, showing not only information resources, but also wisdom. What is especially needed is the wisdom in introducing new information and communication technologies for education and knowledge creation" (ibid). Being merged into building the knowledge-based society and at the same time recognizing the dangers arising from the lack of criticism of the pending processes, the academia raises questions about the social mission of universities. The Polish Rectors Foundation under the Development Programme for Higher Education up to 2020, implemented the project, resulting in the report "The Social Mission of the University in the Twenty-First Century" (Szostek, 2015), on which the dilemmas of modern universities are considered. Among them, the dilemmas of reconciling the traditional academic values with the social servitude, infiltration of academic culture with the corporate culture, combining preparation for life in a democratic society with the preparation for the labour market which is not subject to settlement are enumerated. The questions are asked about the possibility of educating the critical elites in the conditions of mass production of academic education.

Academic education cannot be in any way confined only to the process of educating specialists. It should be a process leading to wisdom, deepening understanding of oneself and the world (oneself in the world). Always to some extent, it should be a humanistic education that appeals to intellect, emotions and will. Gaining wisdom is made, however, not so much by the assimilation of information, but through experiencing and discovering the significance of what is knowledge, and therefore - through the personal experience of its value. Hence, the role of the academic community today remains very special (Jankowska, 2007).

\section{CONCLUSIONS}

So, in the context of the proposed overview of the problem here, the accentuated thought should be read as a contemporary call for the implementation of the classic academic ideas in the conditions of the use of new technologies. Paraphrasing a metaphor of J. Morbitzer, we can say that the modern university institutions should become intellectual arcs that will save humanity from the information deluge, the flood of endless, murky waves to safely bring it to the port of the society in which knowledge will be a resource for creative and innovative activities. A very important task is in the situation of current unprecedented acceleration of technical and technological progress not to lose the deep humanistic character of the educational process in which the modern technology should well serve a man and not contribute to its enslavement.

\section{REFERENCES}

1. Błoński, M. (2016). MITx - New Educational Initiative of MIT. Retrieved 02.04.2016 from : http://kopalniawiedzy.pl/MIT-Massachusetts-Institute-of-TechnologyMITx-platforma-edukacyjna-studia-online-kurs-OpenCourseWare, 14751.

2. Carr, N. (2013). Shallow mind. How Internet affects our brain. Gliwice : Publishing House "Helion", 276 p.

3. Cudowska, A. (2011). Development Trends of Education in the Society of Advanced Modernity. In : Denek, K., Kaminska, A., Kojs, W., Oleśniewicz, P. (Ed.), Education of tomorrow. Axiology, innovation and development strategy. Sosnowiec : Publishing House "Humanitas", pp. 45-60.

4. Drucker P., F. (1969). The Age of Discontinuity: Guidelines to Our Changing Society. London : William Heineman Ltd, $420 \mathrm{p}$. 
5. Giddens, A. (2001). Modernity and Identity. Self and Society in the Late Modern Age. Warsaw : Scientific Publishing House, PWN, 264 p.

6. Goban-Klas, T. (2013). University of 2.0: Progress or Regress? In : Morbitzer, J. (Ed.), Man, Media, Education. Krakow : Publishing House, KTIMA UP, pp. 112-117.

7. Goćkowski, J. (1997). The Functionality of the University in the Perspective of Long Duration. In : The Idea of the University at the End of the Millennium. Warsaw : Foundation for Polish Science, pp. 21-48.

8. Hausman, M. (1999). Electronic Citizen. Wprost, 03.01.1999.

9. Jankowska, D. (2007). Dialogue in the Academy - Tradition and Modernity. In : Jankowska, D. (ed.), In the Academic Space for Dialogue. The Voice of Academic Teachers. Radom : Publishing House, ITE-PIB.

10. Leśniewski, Z. (2013). The Criticism of the Use of Modern Technology in Education. Scientific Papers AON, No 2 (91).

11. Levinson, P. (1999). Soft Edge: Natural History and Future of the Information Revolution. Translation by H. Jankowska. Warsaw : Muza, $276 \mathrm{p}$

12. Lipski, A. (2014). What do We Know about the "Knowledge Society"? Economic Studies, No 167, pp. 116-126.

13. The Social Mission of the University in the Twenty-First Century. (2015). Polish Rectors Foundation, the Conference of Rectors of Academic Schools in Poland. Warsaw : Warsaw Agricultural University.

14. Machlup, F. (1980). Knowledge: Its creation, distribution, and economic signifance. Princeton, New Yersey : Princeton University Press.

15. Misztal, B. (2000). The Privatization of Higher Education in Poland. In : Misztal, B. (Ed.). The privatization of higher education in Poland. Cracov : Universitas.

16. Morbitzer, J. (2014). About Education in the World of New media - an Outline of the Issues. Labor et Educatio, 2, pp. 119-143.

17. Morbitzer, J. (2016). From Hoes to the Computer, Namely the Road to the Information Society. Retrieved 02.04.2016 from : http:/www.wsp.krakow.pl/konspekt/ konspekt8/morbitzer8.html.

18. Morbitzer, J. (2010). The Knowledge Society - Myth or Realistic Goal? In : Denek, K., Kaminska, A., Kojs, W., Oleśniewicz, P. (Eds.). Education of Tomorrow. Education in the Knowledge Society. Sosnowiec : Publishing House "Humanitas", pp. 210-220.

19. Morbitzer, J. (2009). Towards Knowledge Society: Pedagogical Perspective. In : Ciechanowska, D. (Ed.). Studying for the knowledge society. Toruń : Educational Publishers, "Akapit", pp. 13-41.

20. Musiał, E. (2013). School Education in the Face of New Media. In : Denek, K., Kaminska, A., Olesiewicz, P. (Eds.). Education of Tomorrow. Problems of Tomorrow's Education in the Era of Globalization. Sosnowiec : Publishing House "Humanitas".

21. Prensky, M. (2001). Digital Natives, Digital Immigrants. Retrieved 02.04.2016 from : http://marcprenskycom/ariceles- and-publications/.

22. Rifkin, J. (2001). End of Work. Wrocław : Publishing House of Lower Silesia.

23. Sztumski, W. (2008). Paradoxes of the Knowledge Society. Issues of Science, No 11-12.

24. Tapscott, D. (2010). Digital Adulthood. How is the Generation Network Changing Our World. Warsaw : Academic and Professional Publishing House.

25. UNESCO. (2002). Forum on the Impact of Open Courseware for Higher Education in Developing Countries: Final Report. UNESCO, Paris, July 1-3, 28 p.

26. UNESCO. (2005). Toward Knowledge Societies. UNESCO World Report. Condesur-Noireau : Imprimerie Corlet, $226 \mathrm{p}$. 